\title{
KEY SUCCESS FACTORS FOR THE MANAGEMENT OF A SHARED SERVICES BUSINESS UNIT (Article 3 of 3)
}

\author{
TN van der Linde, AL Boessenkool \& CJ Jooste, University of Johannesburg
}

\begin{abstract}
Purpose: The first and second articles in the trilogy introduced shared services as a business model and the various models through which a shared services business can and must evolve to create value. The purpose of this third and final article in the trilogy of articles is to identify the key success factors required to successfully manage a shared services business unit.
\end{abstract}

Methodology: A comprehensive literature study was conducted in order to identify the key success factors required to successfully manage a shared services business unit. This was followed up with an empirical study to determine if organisations that have implemented shared services as a business model are using any of these identified factors to successfully manage their respective shared services business units.

Findings: In the article, a framework is generated to help organisations understand the key success factors required to successfully manage a shared services business unit. This work has further potential in that the key factors required can also be used not only in the normal brick and mortar organisations, but also in virtual organisations.

Implications: This article presents a comprehensive approach to understand the key success factors required to manage a shared services business unit. These findings are important as they can be applied to a conventional organisation as well as a virtual organisation.

Value: This article provides an understanding of the key success factors required to manage a shared services business model. When these key success factors are used as a basis for the management of a shared services business unit, it will continuously create value for the organisation.

Key words and phrases: Service level agreement (SLA), dispute resolution, metrics, continuous improvement, change management, communication, trust, removing boundaries, culture, teamwork and empowerment, people, training, performance measurement, cost, leadership, senior management attitude.

\section{INTRODUCTION}

The first article in the trilogy of articles on shared services introduced shared services as a business model that, if correctly implemented, can lead to both tangible and intangible benefits. The second article in the trilogy provided the framework of the various models (phases) a shared services business unit must evolve through to continuously add value to an organisation. This third and final article in the trilogy of articles presents the key success factors that are required to successfully manage a shared services business unit. These success factors were identified through a literature study as well as through empirical research with organisations that have implemented a shared services business model.

To continuously improve and add value to an organisation, a shared services business unit must transform people, business processes and technology. The key success factors identified in this article thus focus on the transformation of people, business processes and technology. Some of these key success factors are so straightforward that they are often overlooked and taken for granted. These identified key success factors are finally proposed as critical areas that an organisation, and managers of shared services business units, must focus on for the successful management of a shared services business unit.

This article takes the form of a literature study to research the key factors required to successfully manage a shared services business unit. The primary aim of the empirical research was to identify those key success factors that are critical to the management of a shared services business unit. The research was done by means of unstructured personal interviews with representatives of consulting 
firms that have implemented shared services for organisations, as well as representatives of organisations that have implemented shared services.

\section{KEY SUCCESS FACTORS IDENTIFIED THROUGH THE LITERATURE STUDY}

Shared services is an important concept, not only in the context of cost saving or best practises, but from a tactical perspective as well (Schulman, Harmer, Dunleavy \& Lusk, 1999:35). The future success of a shared services business unit is largely dependent on its ability to add value (Forst, 2001:3). The decision and process to implement a shared services business unit is in itself a daunting experience, as it requires the transformation of business processes, people and technology. Once the shared services business unit is up and running, it must be managed, but what key areas need to be focussed on to successfully manage this successfully implemented shared services? Various key success factors were identified through a literature study followed by an empirical study. These key success factors are the basic areas that need to be managed in a shared services environment that will assist managers of shared services business units to add value to their business. It is important that practitioners of shared services take notice of these key success factors, as it will ensure that shared services will not be viewed as a "fad" or a "cost centre", but as a sustainable value-adding business practice.

The adoption of a market- or customer-driven focus is a critical success factor for any business unit, and like any other unit, a shared services centre must provide value if it is to be successful. Managers of shared services business units can now ask: "What key factors do we need to control to be effective, efficient, add value and be customer focussed"? The following key factors were identified through a literature study and empirical research.

\section{Service Level Agreement (SLA)}

Establishing a shared services business unit allows internal clients to choose the type, level and quality of services they want at a price they are willing to pay. The service provider (shared services business unit), on the other hand, can charge an appropriate fee for the services they provide. Internal clients pay the true cost of the service they receive, just as if they had gone to an outside service provider. This means that a shared services unit must not only match the performance levels of an outside service provider, but also exceed the expectations of the customer, or the customer will exercise their right to use alternative service providers. This arrangement or contract whereby the type, level, quality and cost of the services are stipulated is referred to as the service level agreement (SLA). Apart from regulating the relationship between the parties, the SLA also serves as a vehicle to train the client as to the costs of the services (Triplett \& Scheumann, 2000:3). Quinn, Cooke and Kris (2000:150) as well as Schulmann et al. (1999:167) are both of the opinion that an SLA should be kept simple. An SLA should not create a bureaucratic infrastructure with pages of legalistic "what ifs". Quinn et al. (2000:150) are of the opinion that, when the trust between the parties is low, the SLA should address the fears of the parties and will be a more complex document. According to Schulman et al. (1999:167), the principles of an SLA are:

- Keep it simple.

- Keep it brief.

- Use the SLA to factually document the existing service / performance levels.

- Limit the time spent on the non-value added activities.

- Establish responsibilities and metrics for both the shared services centre and the business units.

- Meet and communicate regularly to fix issues quickly.

- Evolve to a more simplified format as trust builds.

- Ultimately there should be no need for a documented agreement.

According to Quinn et al. (2000:151), a service level agreement should answer the following questions in a concise and simple manner:

- What does the client expect?

- What will we supply or deliver?

- How frequently do we need to supply it? 
- To what quality standards?

- At what price?

- What are the clients' obligations?

- What happens if we don't meet these expectations?

- What happens if the client doesn't meet their obligations?

- What recourse do we have if there is failure on either side?

A completed and signed SLA doesn't mean that the end of the SLA process has been reached. According to Triplett and Scheumann (2000:4), it is the beginning of a mutually beneficial relationship that needs continuous improvement and maintenance.

\section{Dispute Resolution}

According to Schulman et al. (1999:169), the biggest fear of a shared services organisation can be summarised in the question: "What if my business partners send me input that is not what has been promised (messy input), but believe I am still responsible for doing what I have agreed to do (value output)?" Each time there is an exception as defined by the SLA, that exception must be captured, tracked, understood, and then fixed. Dispute resolution will be based on the SLA dispute resolution model proposed by Schulman et al. (1999:171) and as presented in Figure 1.

Figure 1: Service level agreement dispute resolution model

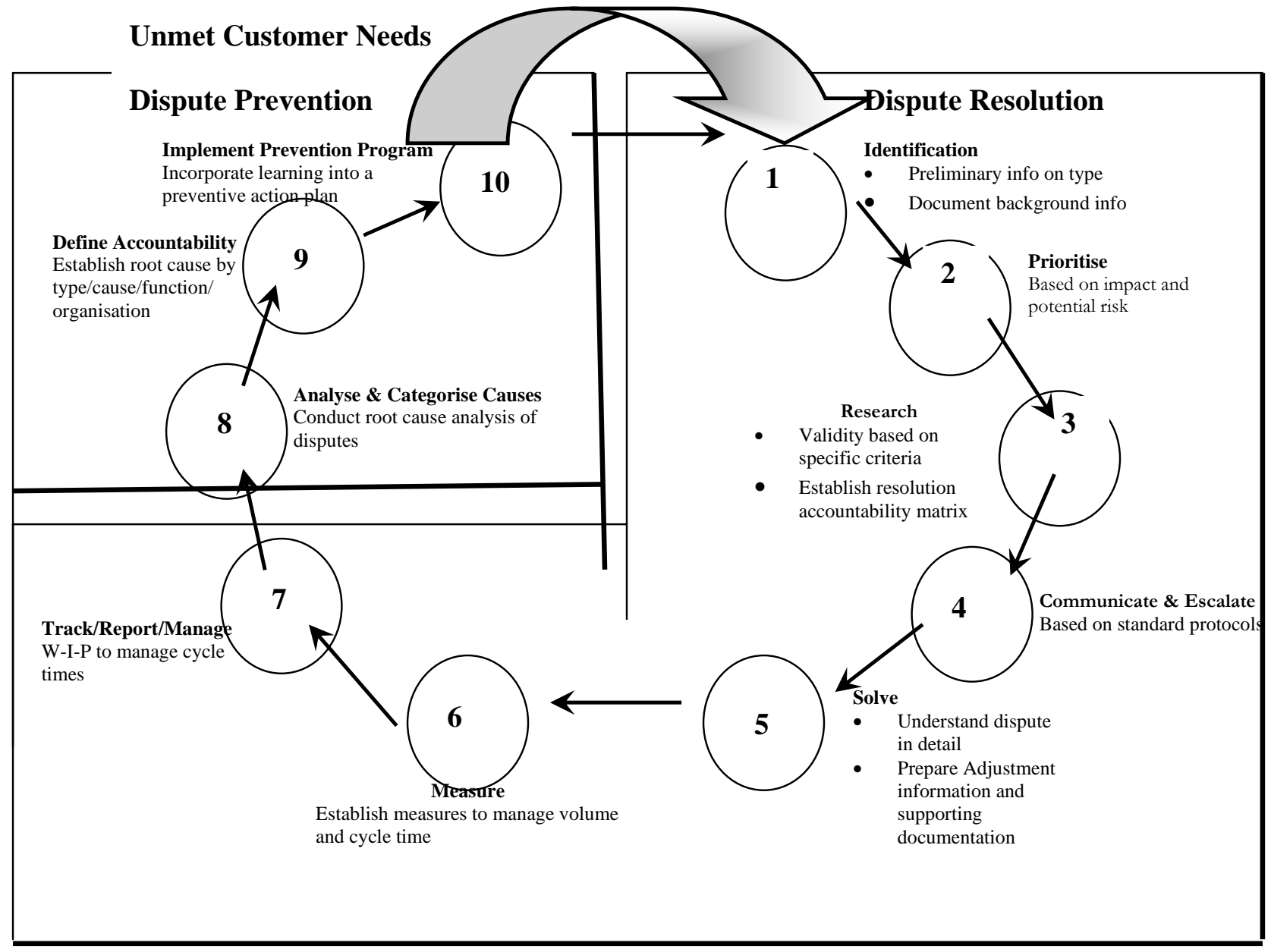

Source: adapted from Schulman et al. (1999:171) 
By using the model, cascading and linking creates an environment in which not only conflict is resolved and prevented, but creates an environment in which continuous improvement can flourish. Schulman et al. (1999:261) are of the opinion that a dispute resolution model should form part of the service level agreement. According to the model, each individual occurrence of conflict is identified for both its "reason" and "cause". The "reason" is why it is an exception (symptom), while the "cause" gets closer to the root of the problem. Problems are prioritised according to the impact on the partner and shared services business unit as well as the potential risk involved. The problem/cause is researched and the results communicated to the service provider and customer. The researched problem is solved and the adjustments documented. Metrics are put in place to measure work in progress (WIP), volume, cycle time and improvements. Accountability is defined according to the root cause, type and function within the organisation. The lessons learned, actions to prevent it from recurring, and improvements are documented in an action plan that becomes part of the SLA.

\section{Metrics}

Shared services groups and the customer need to find ways of fixing a value to what needs to be done and what has been achieved. The process of determining what has been done and fixing a value to it are referred to as performance measures. "Performance measures are like metrics; it measures the same activities that are grouped into an area of focus" Schulman et al. (1999:256). Measuring the success of a shared services business unit is not an easy task. According to Schulman et al. (1999:253), this is due to the following reasons:

- While shared services is not a strategic operation, it is surely tactical (Schulman et al., 1999:35) and must always be taken as an integral part of a corporate strategy. Because of the part it plays in corporate strategy, a wide range of metrics must be developed, from relatively simple metrics at the activity level to measure activity, to macro metrics at the corporate level where strategic performance measures can grade the entire operation.

- Because the relationship between the shared services business and the business units is quite involved, from partnership to customer/supplier, a different set of metrics must be created to measure the relationship, adherence to the SLA, and measuring the value added.

- The end-state vision of a shared services organisation is different from the current operating state and, as such, different sets of metrics will be needed in the advanced market place model and in the basic model.

Metrics should not be used on a day-to-day basis, but they can be tracked and audited by following an entire cascade of metrics. It is also important to keep track of these metrics as they also measure not only team performances, but also the individual team member/employee. Shared services metrics must support management by focussing on activities and processes rather than functions.

Figure 2 illustrates the evolution of metrics from a current state to a shared services organisation. In Figure 2, the relationship between metrics is described as a pyramid cascading down from high-level strategic performance measures to the activity level. The relationship of the pyramids is connected over time as the organisation moves from its current state to a shared services environment. 
Figure 2: Cascading of metrics

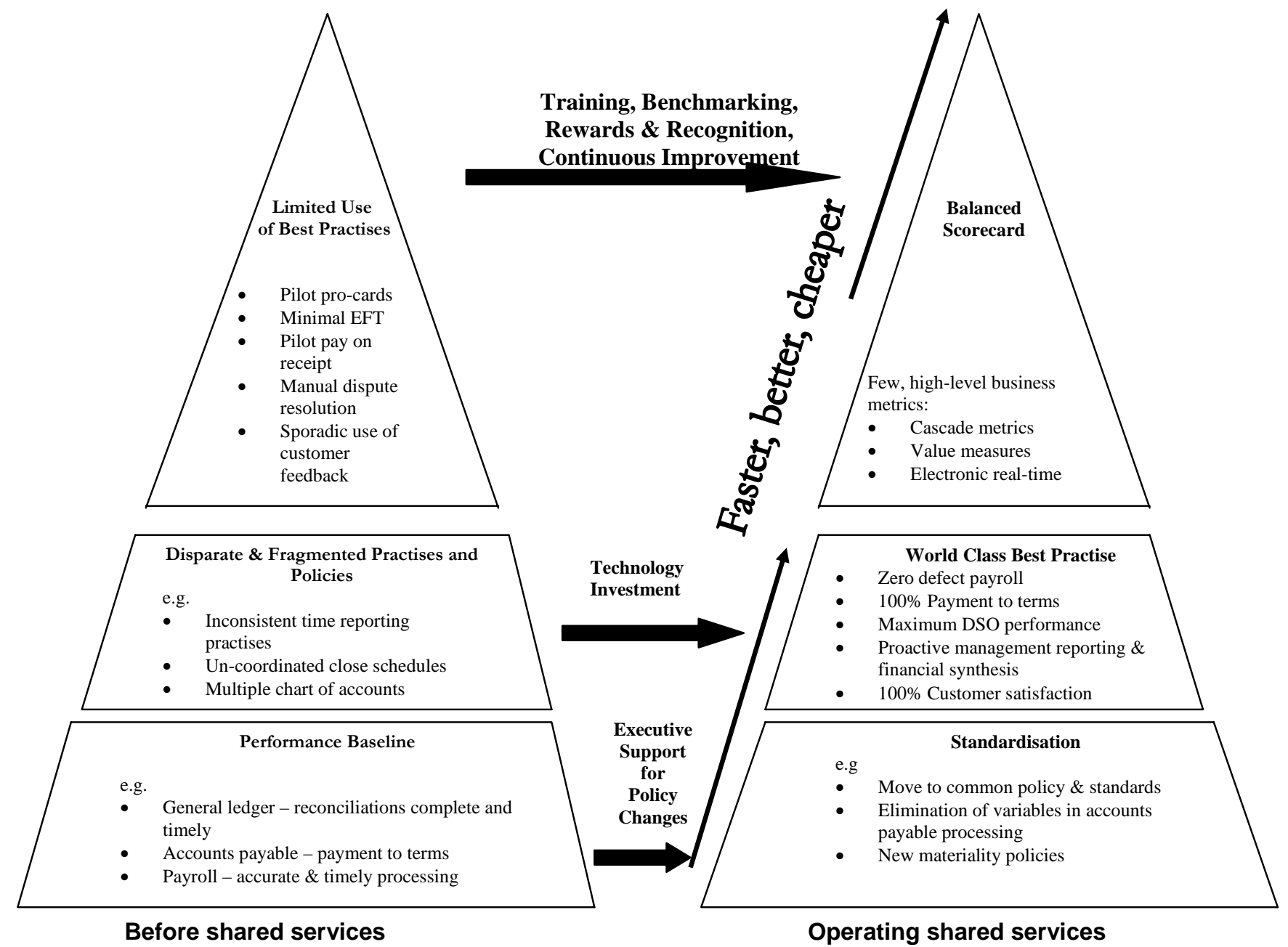

Source: adapted from Schulman et al. (1999:255)

According to Schulman et al. (1999:256), metrics are qualitative calibrations of performance along a single dimension such as time, cost or accuracy. Examples of metrics include the time it takes to process a payment, the accuracy with which a transaction is captured, or the cost to service a printer. From the examples, it can be seen that metrics vary along the dimensions of time, accuracy and costs. The characteristics of the best metrics are the following:

- Metrics are discrete (measuring a single item like transaction process time).

- Metrics are quantitative (the same measurements can be compared).

- Metrics are comprehensible (anyone should be able to understand the metric).

- Metrics must be visual (represented by a graphic i.e. graph, diagram).

Strategic performance measurement takes as its base that the establishment of controls is necessary but in no way sufficient. Schulman et al. (1999:257) is of the opinion that it is harder to create a set of simple metrics that tie operational performance to the strategy than it is to simply measure everything. Strategic performance measurements seek to create a set of simple, well-thought-out and hierarchical metrics that drive success among the following three critical dimensions:

- Strategy. Performance measures provide an ongoing mechanism for measuring the organisation's success in meeting strategic goals. 
- Processes. Performance measures provide actionable, real-time data and use targets for operational excellence in critical processes to create incentives for improvement and resource allocation.

- People. Performance measures align individual objectives with those of the organisation, ensuring organisation-wide commitment to common goals.

The need for constant self-evaluation and external evaluation through the use of quantifiable metrics is a requirement for the successful management of a shared services business unit (Quinn et al., 2000:211). Metrics will also assist management in determining which performances to reward and which to penalise (Cecil, 2000:67).

\section{Continuous Improvement}

Organisations that simply consolidate functions and processes and go no further will cut costs and improve productivity but, after a few years, will experience no further gains. Realising additional gains year after year requires continuous improvement (Cecil, 2000:67). A shared services organisation almost by definition focuses on service delivery and continuous improvement, and must therefore focus on continuous improvement. Continuous improvement goes hand in hand with metrics and benchmarking. According to Quinn et al. (2000:194), "What gets measured, gets done". A benchmark is a measured "best in class practise" level of performance and is recognised as the standard of excellence. Benchmarking is then the process of measuring and comparing ourselves qualitatively and quantitatively against the "best" standards of other similar service providers and organisations (Quinn et al., 2000:91).

Hays (1996:174) is of the opinion that "Learning is a key capability in a continuous improvement culture". In a learning culture, managers and employees who are concerned with customer needs, people and processes that can lead to continuous improvement, should be valued. Hays (1996:175) is of the opinion that, for continuous improvement, an organisation should establish a learning culture that has adaptive mechanisms to gather on-going information (metrics) about the needs that it is trying to serve, and the effectiveness of meeting those needs. Schulman et al. (1999:260) are of the opinion that learning organisations with long-standing continuous improvement programs such as total quality management (TQM) or business process reengineering (BPR) that have moved to a shared services environment, have an advantage with continuous improvement, as continuous improvement is a natural process for them.

\section{Change Management}

Moving from its current state to a shared services environment is a major change in the way an organisation changes. Schulman et al. (1999:239) are of the opinion that resistance to change is the largest danger to a successful shared services organisation. In essence, a shared services organisation strives for excellence. "Many people settle for mediocrity. They resist the idea of striving mightily for excellence"(Bateman \& Snell, 1999:609). The reasons people resist change are presented in Figure 3 and include:

- Inertia. People don't want to disturb the status quo. They are happy in doing things the old way. Process re-engineering frightens them, as it is a deviation from accepted practises.

- Timing. People resist change because of poor timing, either personal (away on leave) or operational (financial year end).

- Surprise. If change is sudden, unexpected or extreme, resistance is a reflexive reaction. You would not say to your transactional team "tomorrow we assume the governance function of travel reimbursements". It should be communicated well in advance, and even with their inputs. Using the conflict resolution model will assist in improvement and change management with new processes. 
- Peer pressure. Teams will resist new ideas, although individual members will not. If the group is cohesive, peer pressure will cause individuals to resist change.

- Self-interest. Teams and individuals will resist change if they think it will cause them to loose something. A shared services organisation not only reduces costs, but also head count. If the financial functions head count has been reduced from 100 employees to 40 employees, a new business process might raise the fear of a further redemption of headcount, which will increase resistance to change.

- Misunderstanding. Even if a new business process or best practise process is implemented, resistance may occur, as team members do not fully understand its purpose.

- Different assessment. This mainly occurs as team leaders and team members differ in their assessment of the new process.

Figure 3: Resistance to change

\section{General reasons for resistance}

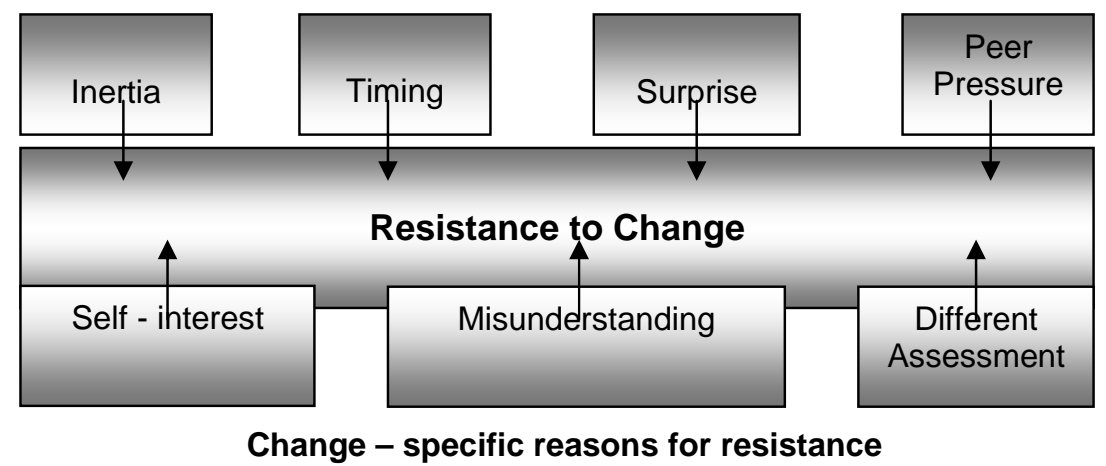

\section{Source: Bateman and Snell (1999:610)}

According to Schulman et al. (1999:239), change is a process, and as such it is manageable. Successful change requires managers to actively lead it. At the forefront of this change management process is a visionary leader. The visionary leader sets tone and direction. The visionary leader must have a ruthless consistency, constantly remind people of why the shared services business unit is doing what it is doing; and solve business problems through benchmarking, best practises and continuous improvement.

Figure 4 represents the change process. The current state is determined; the future state envisioned. Visionary leadership is engaged through clarity, commitment, communication, capabilities, organisation culture, configuration and continuous learning. The shared services business unit is engaged, new processes are implemented to ensure continuous renewal, and the future envisioned state is reached. Here the change process starts again as a new future state is envisioned.

Lucent Technologies addressed change management by talking to people. According to Jim Lusk (Schulman et al., 1999:246), the message conveyed was clear: "Don't do this behind closed doors". Lucent's leadership made a huge effort to get in front of people, not just standing in front and only answering questions. 
Figure 4: Change process

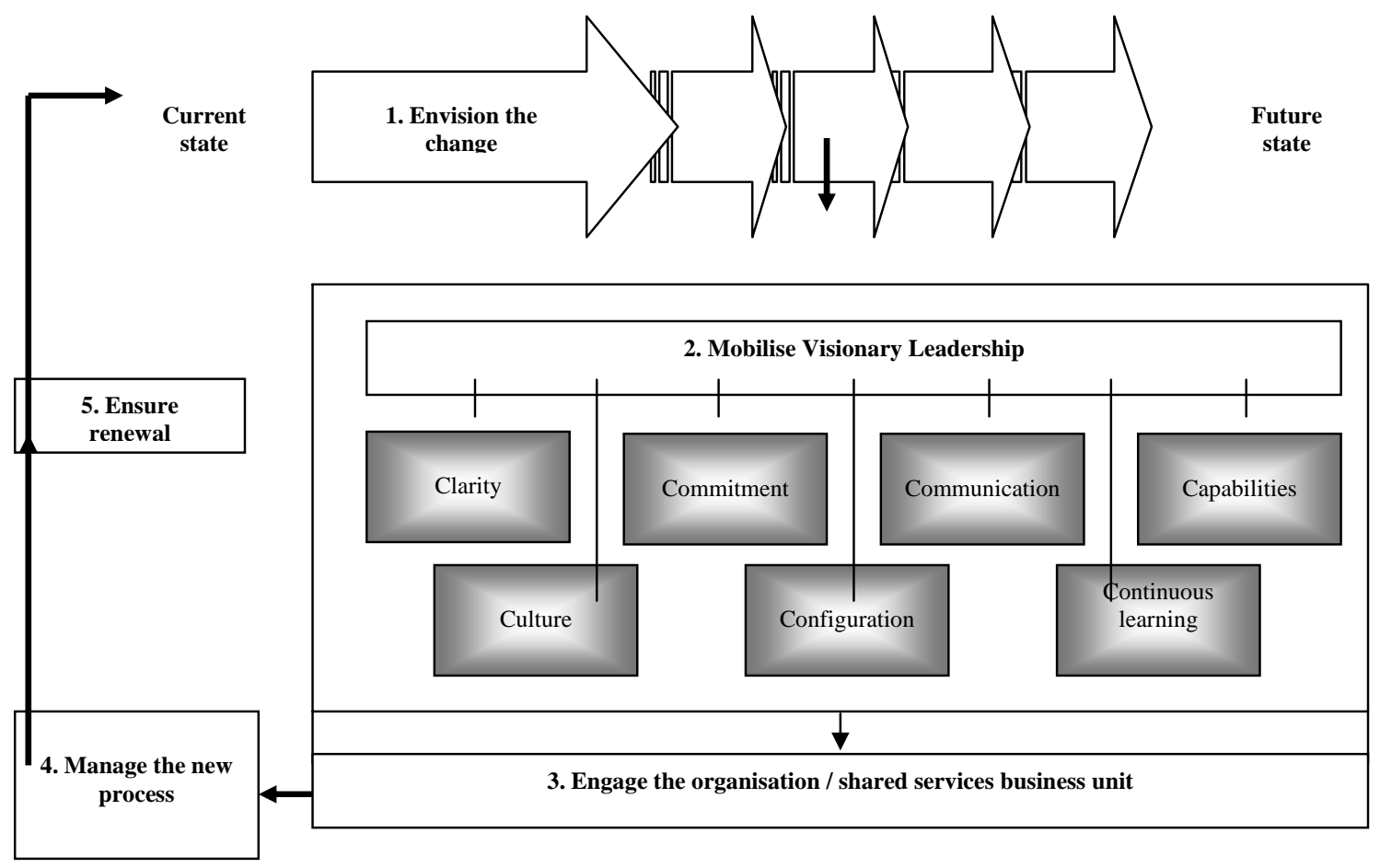

Source: adapted from Schulman et al. (1999:240)

\section{Communication}

Quinn et al. (2000:158) state the importance of communication with the following statement: "Plan to communicate at least ten times more than you expect". Communication in a shared services environment does not only imply communicating with the team members of a shared services business unit, but also with the customer.

Resistance to changing business processes, as well as a culture change from doing a job to add value, was overcome by Lucent Technologies by continuously communicating with people. Jim Lusk from Lucent Technologies (Schulman et al., 1999:248) put the importance of communication as follows: "Face to face dialogues are held constantly with people. A lot of times it meant saying "I don't know". "I don't know" is a very scary thing for a leader to say, but you have to say it. You have to say, "The situation is constantly changing. This is the way I think it will happen, and hope it will happen". Then you need to communicate as soon as something has happened, and that might mean you have to go back and say, "things have changed. We're not able to do it the way I said last week. Instead, we have to do it this way". You must be very open and very honest".

Good communication is also critical towards business units that are the shared services unit's internal customers. Cecil (2000:66) is of the opinion that one area of concern is the inability to drive communication through the organisation. Communicating only a single viewpoint ignores the interest of all the other groups (business units). Shared services units should develop two sets of communication materials; one for the shared services team members and another for their customers, but still convey the same information and message.

Communication between the shared services unit and other business units is a two-way communication. According to Uhlrich (1995:12), "Share information from customer to shared services, and shared services to customer". In a traditional organisation, information is shared on a "need to know" basis and not everyone knows anything. In a shared services organisation, everyone needs to know the customers' expectations. Shared services organisations must learn to share, from technical 
experts working together, professionals being co-located and best practise workshops, and forums where ideas are shared. Uhlrich (1995:12) is of the opinion that a sharing of information through continuous communication builds a shared mindset for the shared services business unit.

\section{Trust}

"Service excellence depends on quality communication regarding service expectation and feedback on services given"(Hays, 1996:59). Good communication depends on the existence of a climate of openness and trust. A low level of inter-business unit trust causes communications to be withheld or distorted, thereby making excellent service almost impossible. Low levels of trust will also lead to the appointment of shadow staff. This is staff appointed in business units to provide the services of the shared services business unit, because the shared services business unit can not deliver what it is suppose to deliver (Uhlrich, 1995:12). Trust requires that employees (team members) of the shared services business unit and the other business units be willing and able to presume competence and good intent in each other's actions. Discussions and interactions, in groups or private, within a high trust environment will build on the underlying assumption that the other party is competent to do their job, and has the good intent to do so.

According to Hays (1996:60), the test to trust occurs when data suddenly arises that indicates a problem between the expectations of the customer and the shared services provider. In a low trust environment, each party will explain the cause of the problem as incompetence or misguided intent by the other party. In a high trust environment, the source of the problem will be determined as the competence, and intent of the parties involved will not be questioned, as competence and good intent are presumed. The existence of the above assumptions sets the stage for a positive and productive work relationship that will add value to not only the shared services business unit, but also to the other organisational business units.

\section{Removing Boundaries}

According to Uhlrich (1995:12), the greatest barrier to the success of a shared services operation is the lingering mindset around boundaries within support functions. Boundaries make distinctions between people in the organisation, generalists versus specialists, compensation versus development versus staffing. Such boundaries create hurdles for the flow of information, work and decision-making. Uhlrich (1995:12) is very clear by stating: "Shared services will not work if boundaries continue to dominate thinking".

The removal of boundaries comes when individuals with different roles and responsibilities within the support function have a shared unity towards the overall goals of the function. Boundaries can be removed by creating a common goal that supersedes each individual goal, by moving individuals around to different roles within the function through career transitions, and by building incentives that encourage boundary-less behaviour.

Uhlrich (1995:13) is of the opinion that a boundary-less business unit also recognises the multiple roles played by the team members. Within the shared services business unit, the functional (human resources, finance, logistics) professional is not a traditional generalist. While the business professional reports to a senior line manager, the individual must be more of a broker of services, a consultant to the management team. Corporate professionals are not just strategic personnel anymore. Much of the work at a shared services business unit is operational. The focus in a shared services office is day-to-day efficiency, not long-term strategy. Corporate professionals do not create and enforce policy, but share expertise.

These new roles created by a boundary-less shared services business unit will create a new set of competencies in consulting skills, team work, business process re-engineering and best practises, which are vital for the management of a shared services business unit.

\section{Culture}

Various authors are of the opinion that a new culture is paramount to the success of a shared services business unit. "Understand that culture is the biggest hill to climb" (Petke, 2001:17), and 
"Create a new culture" (Cecil, 2000:67). According to Jack Welch, "The degree of culture change required to enact shared services successfully is enormous" (Quinn et al., 2000:157).

To make shared services successful, there will have to be a long process of culture change. Quinn et al. (2000:157) are of the opinion that a failure to pay attention to the soft side of change is a recipe for underperformance. Culture change is core to success. "It is what will make shared services endure" (Quinn et al., 2000:157). Bertil Wrethag, ABB's president of support services, said: "We work hard on culture because we wanted a partnership with our clients, but we also knew that unless our own people felt and behaved like partners with each other, we will never get there" (Quinn et al., 2000:158).

Organisational culture is the "personality" of the organisation: It consists out of a collective pattern of beliefs, values, behaviours and philosophy developed over time (Schulman et al., 1999:245). In a shared services environment, these patterns of belief, values, behaviours and philosophy are constantly under pressure of change. Figure 4 illustrates the movement from existing culture to a future state. The odds of successfully managing a shared services business unit grow as the similarity grows between the existing culture and the behaviours and assumptions of the future state.

Figure 4: Existing culture to desired culture transformation

\section{Degree of Consistency:}

The extent to which new beliefs, behaviours and assumptions are in line with the existing culture

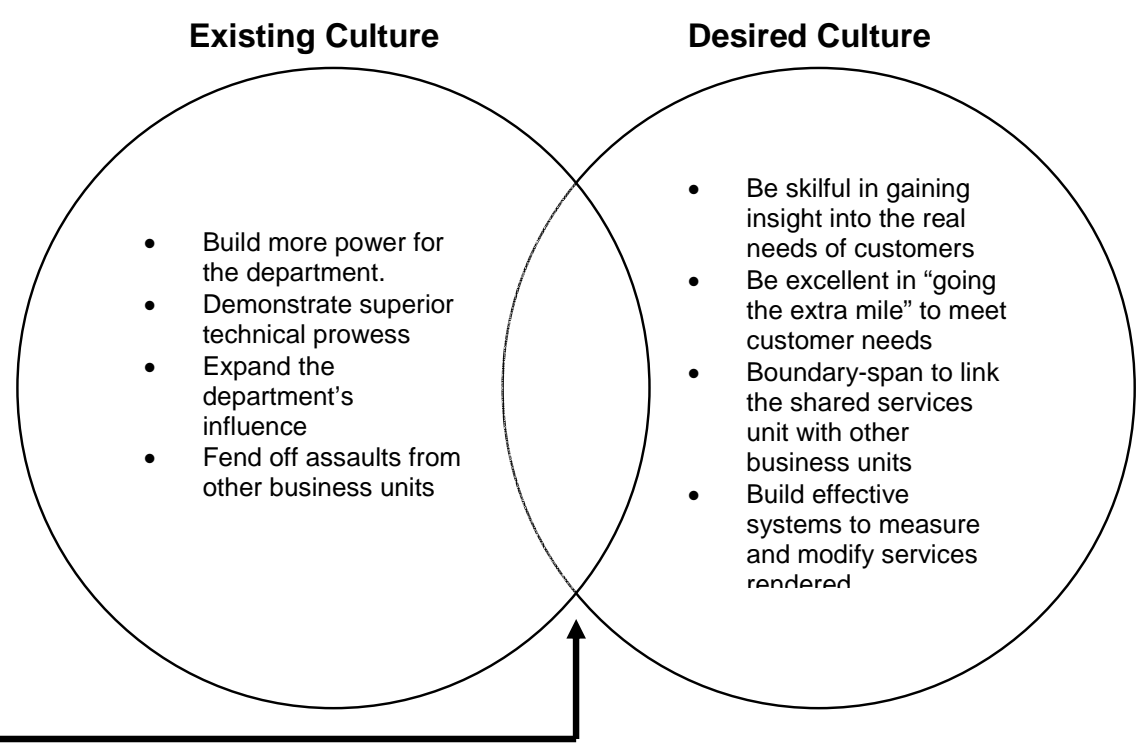

\section{Source: Combined from Schulman et al. (1999:246) and Hays (1996:159)}

When the current culture is in conflict with the desired culture, managers have three options of leading culture changes (Schulman et al.,1999:246):

- Modify the change to be more in line with the existing beliefs, behaviours and assumptions of the culture.

- Modify the beliefs, behaviours and assumptions of the culture to be more supportive of the change.

- Prepare for the change effort and shared services to fail.

Shared services business unit leaders need to take an active and skilful hand in modifying the current state of culture so that a new culture will emerge to genuinely and totally support performance goals. Culture starts at the top. Leaders' ability to successfully understand, realign and build a new shared services culture is a powerful force for creating and reinforcing excellent performance (Hays, 1999:160). 


\section{Teamwork and Empowerment}

Because the typical shared services business unit has a very flat organisational structure (generally three layers), it requires teamwork (Cecil, 2000:67). The shared services business partner must be on both the shared services business team as well as the chief executive officer's management team (Uhlrich, 1995:8). Shared services business unit professionals must be able to join and lead teams to solve a particular problem or concern. The team composition changes as business needs change. The ability to form and deploy teams quickly and effectively is critical to service delivery in a shared services environment.

A key goal then is to empower teams (Cecil, 2000:67). Empowered work teams offer a powerful new resource, but they need to be supported with knowledge and skills (Hays, 1996:169). This implies that teams must be equipped with the necessary tools, skills, knowledge (continuous training) and information to make real and substantive decisions about how their work gets done, as well as empowerment to take the necessary corrective actions.

According to Hays (1996:165), the benefits of empowerment are:

- Empowerment improves response time to customer service delivery needs.

- Empowerment improves response time to recover from service problems.

- Empowerment improves employee job satisfaction and feeling of self worth.

- Empowerment enhances warmth and enthusiasm in customer interactions.

- Empowerment increases opportunities for employees to directly improve services.

Empowerment of individuals and teams is an energising source of improved performance and positive service effectiveness for a shared services business unit (Hays, 1996:165). "Empowering of employees is a great idea but incredibly difficult to make happen" (McEwan, 2001:17).

\section{KEY SUCCESS FACTORS IDENTIFIED BY THE EMPIRICAL RESEARCH}

The empirical research was done through unstructured interviews guided by an interview schedule. In total, eight organisations were interviewed, and the results of the unstructured interviews are presented in Table 1.

Table 1: Key success factors as identified by the respondents

\begin{tabular}{|l|c|}
\hline \multicolumn{1}{|c|}{$\begin{array}{c}\text { Key success factor identified by } \\
\text { respondents }\end{array}$} & $\begin{array}{c}\text { Number of respondents identifying the key } \\
\text { success factor }\end{array}$ \\
\hline People & 8 \\
Communication & 6 \\
Goals and performance measures & 5 \\
Training & 5 \\
Cost & 4 \\
Continuous improvement & 4 \\
Leadership & 3 \\
Senior management attitude & 2 \\
Technology & 2 \\
\hline
\end{tabular}

The key success factors for the management of shared services as identified by the respondents and presented in Table 1 are discussed henceforth. 


\section{People}

All the respondents identified people as a key success factor for the efficient and effective management of a shared services business unit. People will make or break a shared services centre. Right from the design phase, the "right" people must be appointed within the shared services centre. The "right" people will have the ability to adapt to a new environment. The right people will be goaldriven, customer-focused and they will be service-orientated. People also build relationships, not only within the shared services centre and team environment, but also with the customer. These relationships ensure service delivery and add to the success of the shared services business unit. According to one of the respondents, the "wrong" people did not last, and within six months have either been transferred or resigned from the organisation.

\section{Communication}

Communication goes hand in hand with people. According to the respondents, communication is not only the transferring of information to shared services centre members and the internal customers. Communication has a deeper meaning. It involves constantly motivating customers and team members. It requires the continuous marketing of the shared services business unit to its internal customers. It involves communicating to all stakeholders.

\section{Goals and Performance Measurement}

Performance measurement not only measures performance levels, but also sets goals to be met. Without these goals, the shared services business unit only provides another service, as there is no idea as to the levels of service delivery, and no indication of efficiency and effectiveness. All the employees of the shared services business unit must be aware of what the goals are, whether the goals are being met, and if not, what is being done about it. Two of the respondents are of the opinion that the minimum goals to be met must form part of the service level agreement.

\section{Training}

As with communication, training goes hand in hand with people. Employees (team members) constantly need to be trained in respect of new business processes, new business methods, the service they deliver and, last but not least, they need to be equipped with communication skills. Employees of shared services need to be trained in interpersonal relation skills because they are constantly in touch with the customer.

However, training does not only involve the shared services employee. The customer must also be educated. The customer must be educated in terms of what the shared services centre is doing, what it is supposed to do, and what levels of service delivery they can expect. If the customer is not educated, conflict will arise as to who does what and when.

\section{Cost}

Cost, and more specifically the control of cost, was another key success factor identified by four of the respondents. As the lowering of cost was a major force in the establishment of shared services, shared services business units are under constant surveillance as to their cost effectiveness. The respondents were also of the opinion that they are achieving cost savings by being efficient and effective in the transactional processes that they perform.

\section{Continuous Improvement}

The respondents were all of the opinion that continuous improvement is an integral part of the "nature" of shared services. If there is no improvement, customers will get disillusioned and either appoint shadow staff, or move to outsourcing where the perceived best practices will be obtained.

A vital element in the practice of continuous improvement is, according to four of the respondents, "benchmarking'. The shared services business unit has to benchmark against the best in their respective industries. One of the respondents is of the opinion that through their continuous 
improvement and best practises, they are setting industry standards, which are being used for benchmarking.

\section{Leadership}

Three of the respondents are also of the opinion that leadership is a key success factor in the management of shared services. The leader must not only have sufficient shared services knowledge, but must also have the required functional (finance, human resources, procurement) knowledge. Leaders must be able to communicate with the customer, senior management and shared services employees. Above all, leaders must be able to constantly motivate the shared services teams and employees. One of the respondents is of the opinion that leaders with a bad track record within the organisation should not even be considered for a shared services business unit, because the stigma attached to such a person will flow over into the shared services business unit.

\section{Senior Management Attitude}

One of the requirements in the implementation of shared services is senior management "buy-in". If senior management is not committed from the start, that is, from the mobilisation phase of the implementation process, shared services will not be sustainable. One of the respondents is also of the opinion that, due to a lack of senior management commitment, shared services may be relegated to the "not working" file.

\section{Technology}

Advances in information technology have paved the way for shared services. As the implementation of ERP software and shared services are not linked, the implementation can be done in two separate processes. What is required in the implementation and management of shared services is the same enterprise-wide software. One of the respondents was of the opinion that the same version of the ERP software is required throughout the organisation in order to assist in the management of a shared services business unit, and to achieve maximum performance.

\section{MANAGERIAL RECOMMENDATIONS}

Shared services is a delivery method of common business processes that provides efficiency and effectiveness to an organisation implementing a shared services business model. To capitalise on both the tangible and intangible benefits of shared services and further enhance efficiency, effectiveness and add value, shared services managers must manage the key success factors, that is:

- Provide efficient and effective leadership. All the required traits that are required from good leaders should be present in the leader \ manager of a shared services business unit, as well as team leaders. They must be results-orientated through their influence on team members and shared service employees. Managers must be knowledgeable about their functional responsibility and shared services. A team generally only performs as well as its leader.

- People drive processes. It is important that the correct people be appointed in the shared services business unit. The right people will be able to implement new processes, are results driven and are able to transform and adapt to the "new" way of doing business. People establish a culture, which often makes things work or fail.

- Communication is the responsibility of not only the shared services business unit manager, but of all team members. Communication is not to be limited amongst themselves but to the customer as a priority. Talk, talk, and continuously talk to people. Communication is not only about the transfer of information, but also about the establishment of relationships. Communication is about motivating team members and the customer.

- To assist and support shared services employees in their ever-changing environment, they must be constantly trained. Training will supply them with the necessary ability to do things faster, 
better and more accurately. Employees should be multi-skilled and should be able to perform multiple tasks as and when required.

- The culture of a shared services business unit must be one of service delivery. The unit should serve the interests of their customers. Through the culture of service delivery, value will be added to the shared services business unit, the customer, and the organisation as a whole.

- Shared services are supported by technology. The necessary technology is required to support a shared services business unit and the work it delivers. Technology will be leveraged to the benefit of the organisation through effective and efficient utilisation. If the necessary technology is not available, shared services may not be able to function more effectively at a lower cost to the organisation.

- The efficiency and effectiveness of a shared services business unit is dependent on teamwork and empowerment. Teamwork means that it is not "your" work, but "our" work. Team members work together, are multi-skilled and support each other. The individual team members, teams, and team leaders must be sufficiently empowered to make decisions that will enhance the work process, satisfy the customer and add value.

- To know what they must do and up to what standards, a service level agreement (SLA) must be in place. The service level agreement should not be a legal document of the type that will take the shared services business unit time to understand and implement, but a negotiated document that describes the services to be delivered, the extent of these services and the metrics to measure the performance of the shared services business unit.

- One can only effectively manage what one can measure, and therefore the necessary metrics have to be in place. A set of integrated metrics for the shared services business unit will measure end-to-end processes. It should measure the different performance measures and goals from the customer's perspective and not the shared services perspective. The established metrics should measure strategy, processes and people. Metrics used should be contained in the service level agreement.

- Cost savings is one of the major reasons for implementing shared services, and as such are under constant scrutiny by the entire organisation. Cost control is thus of utmost importance in a shared services environment. Cost savings can only be achieved by efficiency and effectiveness. Efficiency and effectiveness can only be achieved through continuous improvement.

- Continuous improvement refers to the establishment of new processes and procedures to do things faster and better. By doing things faster and better, cost savings are incurred, the customer is satisfied, and the shared services centre becomes known for its service excellence. Continuous improvement is achieved by constantly benchmarking against the best and, as such, it strives towards becoming the best.

\section{CONCLUSION}

This article identifies key success factors that are required to successfully manage a shared services business unit. A shared services business unit must know what it has to deliver, what value it must add, and how to add that value. Its customers in return must know what to expect from the shared services business unit. This is all laid down in a service level agreement (SLA). The SLA only guides the shared services business unit in its attempt to deliver service. For the shared services business unit to survive, it must adopt a customer-focused culture through continuous improvement, best practises and benchmarking. To adhere to the service level agreement and to continuously improve, the necessary metrics need to be in place. Service delivery is achieved through continuous communication and empowerment of teams that remove boundaries, and through adopting a new culture that is responsive to the internal customers' requirements and needs. By being responsive, trustworthy and competent in their service delivery, a shared services business unit will not only be successful, but will be truly on its way to an advanced market place model, where its service will be 
rendered in the open market not only to generate revenue for the shared services business unit, but also to become a core business in its own right.

Shared services has become a feasible business strategy for many organisations. Some organisations might be jumping into a shared services model without fully understanding why or how it works. Other organisations might even use shared services to disguise other problems. For these organisations, shared services will become a "fad" rather than a valuable asset. Shared services is not a once-off process, it is a way of living, continuously demanding change and improvement. The first article in the trilogy of articles described what shared services is all about and the change culture that must exist in an organisation to consider a shared service business model. The steps required to implement a shared services business model with the various shared services models was presented in article two. This third and final article identified the key success factors that will assist an organisation that has implemented shared services, as well as managers and employees of shared services, to successfully manage shared services and make it a valuable asset to their organisation.

\section{REFERENCES}

Bateman TS \& Snell SA. 1999. Management. Building competitive advantage. $4^{\text {th }}$ Ed. Boston: Irwin McCraw-Hill.

Cecil R. 2000. Shared services moving beyond success. Strategic Finance, April [Online] Available from: http://infotrac.london.galegroup.com/itweb/rau

Forst LI. 2001. Shared services: a leg up on acquisition payoffs. Business Europe, 41(8) April [Online] Available from: EBSCOHost: Business Source Premier: http://search.global.epnet.com

Hays R. 1996. Internal service excellence. Sarasota: Summit Executive Press.

Mcewan N. 2001. Creating competitive HR shared services for the next generation. Gunn Partners Inc. Paper presented at the shared services for the HR function conference. $24^{\text {th }}-25^{\text {th }}$ September 2001. One Whitehall Place. London.

Petke S. 2001. SAP implementation and beyond - data management on a global scale. Procter \& Gamble. Paper presented at the shared services for the HR function conference. $24^{\text {th }}-25^{\text {th }}$ September 2001. One Whitehall Place. London.

Quinn B, Cooke R \& Kris A. 2000. Shared services: mining for corporate gold. London: Pearson Education Limited (Financial Times - Prentice Hall)

Schulman DS, Harmer MJ, Dunleavy JR \& Lusk JS. 1999. Shared services: adding value to business units. New York: John Wiley \& Sons, Inc .

Triplett A \& Scheumann J. 2000. Managing shared services with ABM (activity based management tools). Strategic Finance March/April 48(2):36,2 [Online] Available from:

http://www.infotrac.london.galegroup/itweb/rau

Uhlrich D. 1995. Shared services: from vogue to value. Human Resource Planning, September 18(3) [Online] Available from: http://infotrac.london.galegroup.com/itweb/rau 